\title{
Advances in the Green Synthesis of Microporous and Hierarchical Zeolites: A Short Review
}

\author{
Tao Pan ${ }^{1}$, Zhijie $\mathrm{Wu}^{1, *(1)}$ and Alex C. K. Yip ${ }^{2}$ (]) \\ 1 State Key Laboratory of Heavy Oil Processing and the Key Laboratory of Catalysis of CNPC, \\ China University of Petroleum, Beijing 102249, China; pantao991@gmail.com \\ 2 Department of Chemical and Process Engineering, University of Canterbury, 8041 Christchurch, \\ New Zealand; alex.yip@canterbury.ac.nz \\ * Correspondence: zhijiewu@cup.edu.cn
}

Received: 18 January 2019; Accepted: 12 March 2019; Published: 17 March 2019

check for updates

\begin{abstract}
Hierarchical zeolites have been extensively studied due to their enhancement of intra-crystalline diffusion, which leads to the improved catalytic activity and resistance to coking-deactivation. Traditional synthesis strategies of hierarchical zeolites via post-treatment or directing synthesis with the aid of mesoporous template are often characterized by high energy consumption and substantial use of expensive and environmentally unfriendly organic templates. In the recent decade, new green synthesis protocols have been developed for the effective synthesis of conventional and hierarchical zeolites. In this review, the latest advancements on the green synthesis of hierarchical zeolites are summarized and discussed in detail.
\end{abstract}

Keywords: zeolite; hierarchical zeolite; hydrothermal synthesis; green synthesis; mesoporous template

\section{Introduction}

Microporous materials, such as zeolite, with at least one pore system in the mesoporous size range (i.e., 2-50 nm), are often referred to as hierarchical zeolites [1]. A hierarchical structure facilitates the access of large reactant molecules to the active center inside the zeolite crystals, while maintaining the acidity and the crystallinity of zeolites. During a catalytic reaction, the reactants enter the active sites inside the hierarchical zeolites through mesoporous channels to undergo the catalytic reaction, and the resulted products leave the zeolite structure through mesoporous channels. As such, the accessibility of the active sites to reactants with a large molecular size is improved (i.e., the diffusion limitation of microporous zeolite is reduced) and thus the catalyst lifetime can be remarkably extended [2]. The improved catalytic performance of hierarchical zeolites has been shown in many catalytic reactions, including alkylation, isomerization, methanol to hydrocarbons (MTH), aromatization, condensation, and catalytic cracking [1-4]. Another striking example is the synchronization of micropore and mesopore structures, which leads to outstanding selectivity in targeted mono-aromatic compounds in biomass pyrolysis [4]. In a hierarchical ZSM-5 zeolite, the opened mesopores produced after the desilication of conventional ZSM-5 can be regarded as "highways" in which large molecules (such as levoglucosan) can diffuse readily to the accessible sites from the pore mouths. In addition, the Brønsted acid sites located on the micropore mouths may also be active for cracking large molecules into small fragments. These fragments then diffuse and form aromatics in the micropores, while the mesopores allow rapid evacuation of the catalytic products. The overall effect from micro- and mesopores enhanced the selectivity to mono-aromatic hydrocarbons.

At present, MFI-, BEA-, MOR-, and CHA-type hierarchical zeolites have been studied in detail [5-7]. The mesopore of hierarchical zeolites can be categorized into two types: with or without an ordered structure. The one with a non-ordered mesopore is generally obtained via the top-down 
method using post-treatment of conventional micro-sized zeolites by acid or base reagents $[8,9]$ or via the bottom-up method by hydrothermal crystallization of aluminosilicate gel without mesoporous templates (i.e., intergrowth of zeolite nanocrystals [10]). In fact, an ordered mesopore could be easily achieved by the bottom-up synthesis method via the crystallization of aluminosilicate gel with the aid of mesoporous templates that generate ordered pores or channels. However, the mesoporous templates need to be removed after hydrothermal synthesis by dissolution or calcination at high temperature. Typically, the mesoporous templates are organic compounds consisting of carbon, nitrogen, sulfur, or phosphorus elements, which inevitably release greenhouse gases and/or toxic gases by calcination. The mesopore size and shape are usually random when mesoporous templates are not used.

Most industrial zeolites are synthesized under hydrothermal conditions from silicate or aluminosilicate gels in aqueous alkaline media at $8-200{ }^{\circ} \mathrm{C}$ for $1-20$ days. The hydrothermal synthesis process is usually not "green" due to the use of organic templates and high pressure, low efficiency, and potential water pollution [11-13]. Such hydrothermal synthesis is inherently challenging from the green chemistry perspective because it depends on the use of organic templates that are ultimately removed by calcination at high temperature, or extraction using an organic solvent [12]. The energy and environmental costs associated with the template removal and the emission of greenhouse gases during combustion of the toxic organic templates are high. Moreover, low concentrations of silicon and aluminum species are often required to compose an aqueous clear solution suitable for the successful crystallization of zeolite. This results in a low yield of zeolite products and requires multiple recycling treatments for the excessive residual solution. Green synthesis of zeolites can be classified into four main categories: (1) synthetic methods that do not require a template or use a recyclable, inexpensive, or renewable template; (2) synthesis of zeolites that use sustainable silicon or aluminum sources; (3) solvent-free methods; and (4) facile synthesis methods, e.g., microwave heating to shorten the crystallization time, solid phase (or quasi-solid phase) synthesis to promote product yield, or continuous-flow synthesis to achieve high productive efficiency [11-13].

In industrial scale, the synthesis of hierarchical zeolite, both top-down and bottom-up methods, involve the emission of environmentally hazardous materials. For instance, the top-down methods via post-treatment produce a large amount of acid or alkali waste solution via dealumination or desilication of the zeolite frameworks. On the other hand, the bottom-up methods also use organic mesoporous templates that are usually toxic and expensive. Thus, direct hydrothermal synthesis without mesoporous templates is still the most robust option. Incorporating green synthetic strategies that are formally used for conventional zeolites into hierarchical zeolite synthesis is deemed to be the most sustainable solution. In this review, we summarize progress on the green synthesis of conventional zeolites, then propose green strategies to solve the problems of hierarchical zeolite synthesis.

\section{Green Synthesis of Zeolites}

Hydrothermal synthesis with organic microporous templates, water, and alkali metals is the most common method of zeolite synthesis. Such a method creates a substantial quantity of waste due to the low yield of zeolite products. On the other hand, decomposing organic templates inside the zeolite products often generates carbon dioxide and nitrogen-containing gases. To tackle the challenges, the concept of green chemistry has been applied to the synthesis of zeolites and four focuses, including the use of sustainable raw materials for zeolite synthesis, avoiding or reducing organic microporous templates, and the development of a facile synthesis method, have been identified.

\subsection{Sustainability of Raw Materials for Zeolite Synthesis}

The use of natural minerals as a sustainable raw material for zeolite synthesis has attracted significant interest in recent years due to their lower costs compared to traditional precursors, such as tetraethyl orthosilicate (TEOS) or sodium aluminate. Pan et al. [14,15] developed a green synthesis route for ZSM-5 zeolites using kaolin as a raw material for chemical silicon and aluminum source. Later, Li et al. [16] realized the synthesis of ZSM-5/MCM-41 composite zeolites using kaolin. 
Chaisena et al. $[17,18]$ studied the synthesis of zeolites from diatomite and they found that the resulting zeolites, such as $\mathrm{NaP}$ zeolite, analcime, and sodalite, were highly dependent on process parameters, including initial gel composition, crystallization temperature, and time. Zhang et al. [19-21] used diatomite as a raw material to synthesize hierarchical ZSM- 5 zeolites by an in-situ crystallization method. Jia et al. [22] synthesized silicalite-1 zeolites by means of steam-assisted crystallization with diatomite. Li et al. adopted a vapor-induced transformation to directly synthesize ZSM- 5 zeolites from a natural clay, namely attapulgite, as a low-cost and environmentally benign $\mathrm{Si} / \mathrm{Al}$ source, in which the yield of zeolite reaches $96 \%$ [23].

Besides natural minerals, the residue of natural resources containing silicon or aluminum has also attracted a lot of attention. Missengue et al. [24] synthesized ZSM-5 zeolites with a very high purity using South African coal fly ash as the sole precursor. Liu et al. also reported that zeolite P1 could be synthesized from fluidized bed fly ash [25]. Recently, white rice husk silica and rich hush ash have been suggested as possible raw material alternatives for ZSM-12 and ZSM-5 zeolite, respectively [26-28].

\subsection{Reducing/Avoiding Organic Templates for Zeolite Synthesis}

Many attempts have been made to reduce organic templates or develop sustainable templates for zeolite synthesis [29].

First, an effective technology for recycling organic templates should be developed. Davis et al. [30,31] successfully developed solvent extraction treatments to remove organic templates from zeolite micropores. The amount of template that can be removed by extraction is found to be dependent on the size of the template and the interaction of the templates with the zeolite framework, in which organic materials that combust in TGA experiments below $400{ }^{\circ} \mathrm{C}$ can be extracted from the zeolite micropores when the template is smaller than the micropore opening (i.e., tetraethylammonium (TEA) in BEA zeolite (0.7 $\mathrm{nm}$ aperture size). Takewaki et al. [32] found that TEA cations inside AFI zeolite $(0.73 \mathrm{~nm}$ aperture size) micropores can be completely extracted and recycled by acetic treatment in an aqueous solution.

Second, low-toxicity or biodegradable organic templates for zeolite synthesis can be developed, especially organic templates that originate from biomass materials. Xiao et al. [33] prepared $\mathrm{AIPO}_{4}-5$ zeolite using organic guanidine as a template agent.

Third, synthesis routes that do not use organic templates (namely, the template-free synthesis method) [34-43], including modulation of initial aluminosilicate gel ratios, introduction of zeolite directing agents, introduction crystallization seeds, and interzeolite conversion, have also been developed. Recently, a surfactant-templating method by replacing conventional organic templates with a surfactant has also been developed as one of the most effective and versatile synthetic strategies for bridging the gap between zeolites and amorphous mesoporous molecular sieves [44].

For the modulation of initial aluminosilicate gel ratios, gel ratios are adjusted by changing the atomic/molecular ratios of $\mathrm{Si} / \mathrm{Al}, \mathrm{H}_{2} \mathrm{O} / \mathrm{SiO}_{2}, \mathrm{OH}^{-} / \mathrm{SiO}_{2}$, and $\mathrm{Na}_{2} \mathrm{O} / \mathrm{SiO}_{2}$. Grose and Flanigen $[34,35]$ synthesized a ZSM- 5 zeolite with high crystallinity in a $\mathrm{Na}_{2} \mathrm{O} / \mathrm{SiO}_{2} / \mathrm{Al}_{2} \mathrm{O}_{3} / \mathrm{H}_{2} \mathrm{O}$ system without an organic template. Li et al. [36] developed a rapid route to directly synthesize a ZSM-5 zeolite solely from sodium silicate, inorganic acid, and aluminum salt (i.e., aluminates) in an aqueous solution, in which a high yield of zeolite product within a relatively short crystallization time can be achieved by composing the precursor of gels with a high silicon content. Xiao et al. [37] successfully synthesized an ECR-1 zeolite by modifying the $\mathrm{Na}_{2} \mathrm{O} / \mathrm{SiO}_{2}$ ratio without an organic template.

For the introduction of a directing agent, a directing agent solution containing the basic structural unit of the target zeolite is required. Rubin et al. [38] found that ZSM-34 zeolite possesses two topological structures involving OFF and ERI, in which both structures contain the basic unit of CAN cage. Interestingly, L zeolite is characteristic of the structure of the CAN cage. Xiao et al. $[39,40]$ successfully synthesized a ZSM-34 zeolite by introducing an L zeolite directing agent into the synthesis system. For the introduction of crystallization seeds, a small number of zeolite crystals is introduced to the precursor of the same zeolite to direct the crystallization via promoting the crystallization rate and 
thus avoiding the formation of hetero-crystalline phases. This synthetic strategy has been developed for the preparation of BEA, RUB-13, ZSM-12, LEV, and SUZ-4 zeolites [41].

Sano et al. found that BEA, CHA, LEV, RUT, and MFI zeolites could be successfully synthesized by the interzeolite conversion of FAU-, BEA-, and LEV-type zeolites as starting materials under various hydrothermal synthesis conditions [42]. Geol et al. also utilized FAU and BEA zeolites as parent materials to synthesize high-silica MFI, CHA, STF, and MTW zeolites with the aid of alkaline [43].

\subsection{Development of Facile Synthesis Methods}

The conventional hydrothermal synthesis requires long-term crystallization with a low product yield via batch production in an autoclave, resulting in low production efficiency. Thus, facile synthesis methods for zeolites have been focused on increasing the crystallization rate, developing continuous-flow synthesis, or simplifying post-treatment of a residual solution after synthesis via enhancing the product yield. There are four typical methods for the facile synthesis of zeolites, including ionothermal synthesis, solid-state or quasi-solid-state (with high solid concentration) synthesis, microwave- or ultrasonic-assisted synthesis, and continuous-flow synthesis.

First, the ionothermal synthesis method is characteristic of the use of ionic liquid as the solvent and the template, in which the high-pressure hazard caused by water vapor is avoided. In 2004, Cooper et al. [45] reported the first synthesis of aluminophosphate and silico-aluminophosphate zeolites by ionothermal systems. Morris et al. $[46,47]$ extended the synthesis of aluminophosphate to aluminosilicate zeolites using ionic liquids as solvents.

Second, the solid-state or quasi-solid-state synthesis method requires the composition of zeolite precursors with a high solid content. The typical quasi-solid-state synthesis method is the dry gel conversion developed by $\mathrm{Xu}$ et al. [48], in which only a bit of solvent (i.e., water) is required. Dou et al. [49] successfully prepared ZSM-5 zeolite in an extremely concentrated solid-phase system using a solid-state silicon source and organic composite surfactant, in which the enhanced crystallization rate and product yield were observed. Similar work has also been observed on the synthesis of LTA zeolites [50]. On the other hand, the solid-state synthesis method has been commonly regarded as a solvent-free synthesis method since the work of Xiao [51-53]. Xiao et al. [51,52] reported a solid-state synthesis method for zeolite, in which the initial solid raw material was ground and mixed without adding any reaction solvent. At present, LTA, BEA, MFI, CHA, and ITQ zeolites as well as MOR/ZSM-5 zeolite composites have been achieved [54-61].

Third, the microwave-assisted method is generally considered to be a green chemical process with mild reaction conditions and a high crystallization rate [62-67]. Since the first attempt to synthesize $\mathrm{NaY}$ and ZSM- 5 zeolites by Mobil in 1988 [62], aluminophosphate zeolites have also been prepared with the aid of microwave by Girnus et al. [63] and Pang et al. [64]. In addition, an ultrasonic-assisted method has been developed to promote the nucleation rate of zeolites and thus accelerate the crystallization rate [68].

Last, continuous-flow synthesis of zeolites is characteristic of complete crystallization in a matter of seconds or minutes using a tubular reactor due to the large heat transfer coefficient, and is therefore also called "ultrafast synthesis" [69-71]. Okubo et al. reported that the crystallization from amorphous aluminosilicate gel to full crystallinity ZSM- 5 zeolites requires just tens of or even several seconds, and about $10 \mathrm{~min}$ for the formation of mordenite zeolite and BEA zeolite, respectively [69,70]. The synthesis on the order of seconds or even minutes provides great potential to facilitate the mass production of industrial zeolites (i.e., ZSM-5, BEA, and mordenite zeolites).

Table 1 summarizes the comparison of the applicability, water consumption, and product yield of the reported green synthesis method for zeolites. Unlike the FAU-type zeolite synthesized without organic templates, MFI- and BEA-type zeolites conventionally require tetrapropylammonium (TPA) and TEA cations, respectively, and are available for various green synthesis methods, perhaps due to the good thermal stability of both zeolites. Obviously, microwave-assisted synthesis is characteristic of high energy efficiency with a large crystallization rate. The use of kaolinite, diatomite, or rich husk 
ash as raw materials leads to a certain $\mathrm{Si} / \mathrm{Al}$ ratio of zeolite product that depends on the mineral composition. The strategy of recycling an organic template seems to be only suitable for special zeolites. Similar results can be observed with the green methods by developing low-toxicity or biodegradable template and the ionothermal synthesis. Thus, synthesis without organic templates or the solid-state/quasi-solid-state synthesis is more suitable for green synthesis due to outstanding advantages including excellent applicability of variable zeolite types, a low amount of water required, and a high product yield.

In the past two decades, various methods for hierarchical zeolite synthesis have been developed, which can be classified into two categories: top-down and bottom-up synthesis [6,12,72]. The top-down approach begins with microporous zeolites and subsequently involves post-treatment (typically acid/base treatment) to obtain a hierarchical structure inside zeolites. The efficiency of the formation of a mesopore pore via post-treatment is strongly dependent on the severity of treatment conditions, in which strong alkali or acid reagents, and harsh treatment conditions, are common in desiliconization or dealumination, respectively. Green attempts at changing the typical strong alkali or acid reagent into a relatively weak alkali or acid reagent (i.e., acetic acid, ammonia, or water steam), which are less harmful to the human body, have been developed. However, water pollution via post-treatment is still inevitable. Unlike the top-down method, the bottom-up method usually involves simultaneous formation of a micropore that originated from the zeolite framework with the aid of microporous templates and mesopore structure with the aid of mesopore-directing templates, which can be removed via the same routes as microporous templates. As such, secondary water pollution via post-treatment is avoided. Here, we mainly focus on the bottom-up method via direct synthesis of hierarchical zeolites, in which principles for the green synthesis of conventional microporous zeolites are also suitable for hierarchical zeolites. 
Table 1. Methods for the green synthesis of zeolites.

\begin{tabular}{|c|c|c|c|c|c|c|c|c|c|c|c|}
\hline \multirow{2}{*}{$\begin{array}{c}\text { Green Strategy } \\
\text { Methods }\end{array}$} & \multicolumn{2}{|c|}{ Sustainability of Raw Materials } & \multicolumn{5}{|c|}{ Avoiding or Reducing Organic Templates } & \multicolumn{4}{|c|}{ Facile Synthesis Method } \\
\hline & $\begin{array}{l}\text { Nature } \\
\text { minerals }\end{array}$ & Rich hush ash & $\begin{array}{l}\text { Low toxic } \\
\text { template }\end{array}$ & $\begin{array}{l}\text { Recycling } \\
\text { template }\end{array}$ & $\begin{array}{l}\text { Template-free } \\
\text { by modulating } \\
\text { initial gel }\end{array}$ & $\begin{array}{l}\text { Template-free } \\
\text { using zeolite } \\
\text { seeds }\end{array}$ & $\begin{array}{l}\text { Interzeolite } \\
\text { conversion }\end{array}$ & $\begin{array}{l}\text { Ionothermal } \\
\text { synthesis }\end{array}$ & $\begin{array}{l}\text { Solid-state or } \\
\text { quasi-solid-state } \\
\text { synthesis }\end{array}$ & $\begin{array}{l}\text { Microwave-assisted } \\
\text { synthesis }\end{array}$ & $\begin{array}{c}\text { Continuous-flow } \\
\text { synthesis }\end{array}$ \\
\hline Zeolite type & $\begin{array}{c}\text { MFI, BEA, FAU, } \\
\text { MWW, ATP, } \\
\text { MOR, TON } \\
\text { [14-23] }\end{array}$ & $\begin{array}{c}\text { GIS, MFI, } \\
\text { MTW [25-28] }\end{array}$ & AFI [33] & $\begin{array}{c}\text { MFI, BEA } \\
\text { [30] }\end{array}$ & $\begin{array}{c}\text { MFI, EON } \\
{[36,37]}\end{array}$ & $\begin{array}{c}\text { BEA, MFI, } \\
\text { MOR, SZR } \\
{[41,66]}\end{array}$ & $\begin{array}{l}\text { BEA, CHA, } \\
\text { LEV, RUT } \\
\text { MFI [42-44] }\end{array}$ & $\begin{array}{c}\text { AEI, SOD } \\
{[47]}\end{array}$ & $\begin{array}{c}\text { (MFI, MOR, } \\
\text { BEA, FAU, LTA, } \\
\text { CHA, ITQ } \\
\text { [49-61] }\end{array}$ & $\begin{array}{l}\text { AFI, LTA, BEA, } \\
\text { FAU, MFI }[63,65]\end{array}$ & $\begin{array}{c}\text { MOR, MFI, BEA } \\
{[69-71]}\end{array}$ \\
\hline $\begin{array}{l}\text { Calcination for } \\
\text { organic removal }\end{array}$ & Yes & Yes & Yes & No & No & No & No & Yes & Yes & Yes & Yes \\
\hline $\begin{array}{c}\text { Water } \\
\text { Consumption } \\
\left(\mathrm{mL} \mathrm{g}_{\text {zeolite }}{ }^{-1}\right)^{1}\end{array}$ & $\begin{array}{c}10.65 \text { (ZSM-5) } \\
\text { [14] }\end{array}$ & - & $2.3[33]$ & $134[30]$ & $8.9[36]$ & $4.3[41]$ & $65-90[42]$ & 0 & $\sim 0$ & $16.8[63,65]$ & $\sim 8$ \\
\hline $\begin{array}{l}\text { Product yield } \\
\text { based on } \mathrm{Si} / \mathrm{Al} \\
\text { source }^{2}\end{array}$ & $\begin{array}{c}85 \% \text { [14], } 96 \% \\
\text { [23] }\end{array}$ & General & Genera & General & General & General & $46-76 \%[42]$ & General & $\begin{array}{c}\text { High (93-95\%) } \\
\text { [50] }\end{array}$ & General & General \\
\hline
\end{tabular}

${ }^{1}$ Water consumption is calculated from the composition of zeolite precursor and the conversion of silicon and aluminum species to zeolite product. ${ }^{2}$ "General" means the yield of as-prepared zeolites is similar to that of zeolites from conventional hydrothermal synthesis or commercial corresponding zeolite, and "high" indicates a higher crystallinity. 


\section{Green Synthesis of Hierarchical Zeolites}

\subsection{Green Synthesis of Hierarchical Zeolites via Mesoporous Templates}

Numerous materials have been found to be useful as mesoporous templates for the synthesis of hierarchical zeolites, which can be subdivided into the hard template and the soft template depending on whether the template interacts with zeolites' precursors [73-75]. The use of carbon materials as hard templates is not sustainable because of the post-treatment of crystallization zeolite products accompanied by massive energy consumption and high greenhouse gas emissions. In recent years, researchers have attempted to use environmentally friendly and sustainable materials, such as silica spheres, sucrose, starch, and calcium carbonate nanoparticles, as hard templates to prepare hierarchical zeolites. Machoke et al. [76] reported on the use of silica spheres as hard templates and silicon sources, as shown in Figure 1.

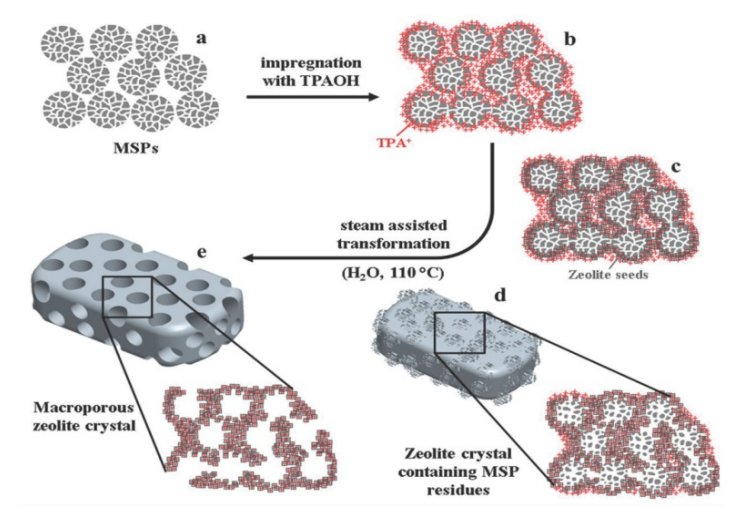

Figure 1. Schematic representation of the crystallization process of hierarchical zeolite crystals. (Reprinted with permission from [76]. Copyright: 2015, John Wiley and Sons).

Figure 1 shows that single-crystalline zeolites embedded with macropores can be prepared by the vapor-phase transport method with a trace amount of organic templates (tetrapropylammonium hydroxide, TPAOH). Song et al. [77] synthesized a hierarchical ZSM-5 zeolite via a one-step in-situ hydrothermal carbonization with a steam-assisted crystallization process using sucrose as a mesoporous template precursor. Clearly, the reduction of organic template amount or the use of a biodegradable carbon template precursor can be ascribed to the green protocol. However, large energy consumption is still required in the preparation process because the calcination is still required to remove carbon-related compounds. In recent decades, inorganic materials have been developed as mesoporous templates to replace carbon templates. Zhu et al. [78] used calcium carbonate nanoparticles as hard templates to prepare hierarchical Silicalite-1 zeolite. Calcium carbonate can be easily removed by washing with an acid solution, leading to a large number of intra-crystalline mesopores. The resulting $\mathrm{CaO} /$ zeolite composite material with dual functions of acid and alkali could be obtained after being calcined at high temperature, leading to a bifunctional hierarchical zeolite catalyst suitable for acid-base catalytic reactions. Besides the inorganic oxide materials, natural carbonaceous organic materials (i.e., sucrose, starch, etc.) can be used as hard templates to replace conventional carbon materials (i.e., activated carbon, carbon particles, and carbon nanotubes). However, the required carbonization and calcination processes for zeolite synthesis still lead to the emission of excess greenhouse gases. Thus, the direct use of inorganic oxides as hard templates, such as calcium carbonate and silica, can be regarded as a green choice. Silica spheres can be used as templates and silicon sources to prepare macroporous/microporous MFI zeolites.

Unlike hard templates, soft templates can interact with a zeolite precursor or framework through covalent bonds, van der Waals forces, hydrogen bonds, or electrostatic forces, and thus participate in the crystallization process of the zeolites [79]. Thus, a controllable mesopore structure can be achieved via screening soft templates. The green synthetic strategy of using a low-toxicity or biodegradable 
polymer as a soft template has been a focus of research. Xiao et al. [80] reported on a low-toxic cationic polymer of polydiallyl dimethyl ammonium chloride (PDDA) as a mesoporous template to synthesize zeolites with 4-50 nm mesopores, and the mesopore size can be adjusted by varying the PDDA amounts. In particular, hierarchical BEA zeolites could be prepared by PDDA without microporous templates (i.e., TEA cations), usually used for conventional hydrothermal synthesis [81], suggesting the bifunctional template roles in zeolite crystallization. PDDA can also be used as a bifunctional template for the synthesis of certain topological structures (BEA, MFI, etc.), thus avoiding the use of microporous templates and making the preparation process relatively economical and simple. Shi et al. [82] modified the surface of chitosan to form cations and succeeded in synthesizing hierarchical zeolites.

For the soft template methods, synchronization of the micropore and mesopore organic templates is the key to the formation of the target hierarchical zeolite [83]. Generally, the conditions for hierarchical zeolite synthesis are harsh [84]. The use of organosilane as a template can solve the problem of phase separation between mesopore organic templates and zeolite units [85]. The organosilane containing a special functional group, such as a trimethoxy group or a bifunctional surfactant, can be directly used for converting a hydrogel to the hierarchical zeolite. However, these templates have the disadvantages of complicated structures and high cost. Low-toxicity, low-cost, and easily available polymers (polyvinyl alcohol [86], polyvinyl aldehyde [87], etc.) are more sustainable choices. It should be noted that polymers still need to be removed by calcination.

\subsection{Green Synthesis of Hierarchical Zeolites without Mesoporous Templates}

In reference to the sustainability of reducing/avoiding organic templates in conventional microporous zeolite synthesis, the synthesis of hierarchical zeolites without mesoporous templates is generally regarded as a green synthesis method. At present, this method can be categorized into three types: intergrowth of zeolite nanocrystals, steam-assisted crystallization (SAC), and salt-assisted seed induction.

\subsubsection{Intergrowth of Zeolite Nanocrystals}

For the intergrowth of zeolite nanocrystals to inter-crystalline mesopores, microporous templates and a special hydrothermal synthesis condition of the aluminosilicate gel are generally required to synchronize the nucleation rate and growth rate in zeolite synthesis [88]. Zhang et al. [89] synthesized pillared MFI/MEL symbiotic zeolite nanosheets using tetrabutylphosphonium hydroxide or tetrabutylammonium hydroxide as a microporous zeolite template. The zeolite nanosheets have a thickness of $2 \mathrm{~nm}$, and they are symbiotic and perpendicular to each other, forming particles of $100-200 \mathrm{~nm}$, and the mesoporous structure is derived from the vertically stacked voids between the nanosheets.

Previously, we [88] developed a synthesis strategy for hierarchical ZSM-5 zeolites using a TPA cation as the microporous template and via the intergrowth of zeolite nanocrystals under the high solid content system by controlling the alkalinity and pre-crystallization process. Partial depolymerization of silica (as a silicon source) occurs in the zeolite precursor system with a high solid content and alkalinity, and the resulting depolymerized silica forms a reactive silicon source with a certain size and suitable pore structure for the growth of zeolite. TPA cations and aluminum species in the system can assemble simultaneously on the surface and interior of the active silicon source and grow into nanocrystals after nucleation. Zeolite nanocrystals formed by in-situ crystallization relate to the nanocrystals grown by the same silicon source, leading to the formation of inter-crystalline mesopores via intergrowth of ZSM-5 zeolite crystals, as shown in Figure 2. Bein et al. [90] and Wang et al. [91] also attempted to use a highly concentrated gel to promote the nucleation of zeolite nanocrystals, respectively. First, they prepared a concentrated zeolite precursor gel $\left(\mathrm{SiO}_{2} / \mathrm{H}_{2} \mathrm{O}=1 / 6.8\right)$ for $\mathrm{BEA}$ zeolite, and then carried out the crystallization at a high temperature of $150{ }^{\circ} \mathrm{C}$. Aggregates of zeolites with inter-crystalline mesopores were formed. Clearly, the formation of inter-crystalline mesopores is 
dependent on the aggregation of zeolite nanocrystals. It is well known that the size of zeolite crystals during hydrothermal synthesis is determined by the formation rate of the zeolite nuclei and the growth rate of zeolite crystals, in which rapid nucleation prefers small zeolite crystals. Therefore, hierarchical zeolites with inter-crystalline mesopores are frequently reported in solid-state or quasi-solid-state synthesis [88-94], in which a high solid content in the hydrothermal system contributes to a high supersaturated concentration, leading to an enhanced nucleation rate. The use of a mother liquid of the target zeolite to promote the nucleation of zeolites [95] and the development of two-step crystallization to separate the nucleation and crystal growth period [96] have been shown to be effective routes to prepare hierarchical zeolites.
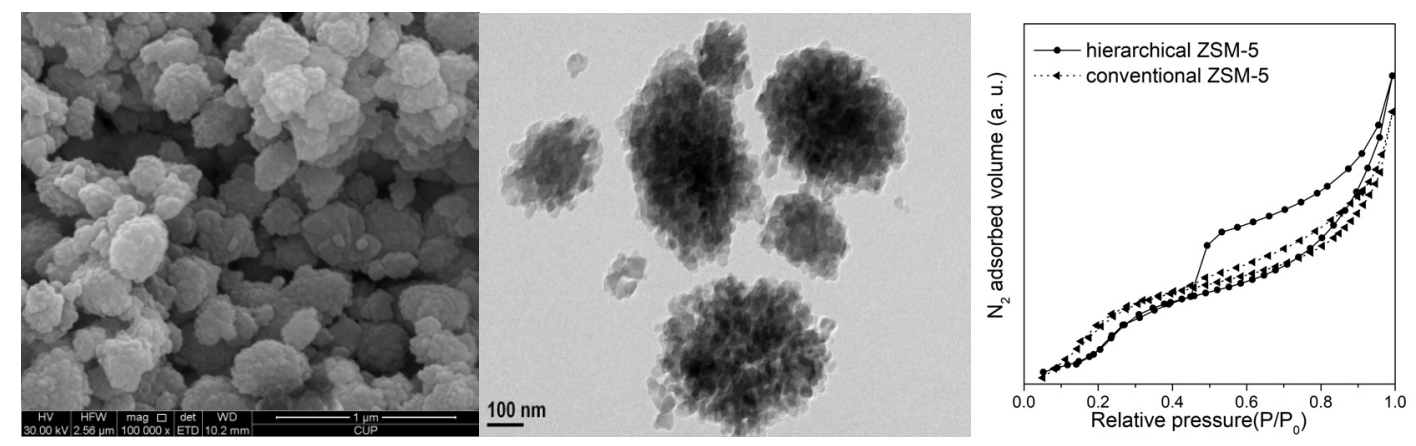

Figure 2. SEM (left) and TEM (middle) images and $\mathrm{N}_{2}$-sorption isotherm (right) of hierarchical ZSM-5 zeolites.

To promote the efficient nucleation of zeolite crystals, Mintova et al. incorporated microwave heating into the hydrothermal synthesis of nano-sized zeolites [97-99]. Compared to conventional heating, the microwave-assisted hydrothermal method provides an efficient way to synthesize various zeolite nanocrystals and better control of their particle size distribution, yield, phase purity, and morphology by careful adjustment of synthetic conditions (i.e., crystallization temperature, pressure, and time). Interestingly, in addition to the above bottom-up approach for the fabrication of zeolite nanocrystals, Wakihara et al. [100] reported a new method for the top-down production of zeolite nanocrystals by milling micro-sized zeolites to produce zeolite nanoparticles, in which the outer portion of the zeolite framework is destroyed and can be recrystallized in a dilute aluminosilicate or silicate solution after bead-milling. The combined bead-milling and post-milling recrystallization yielded zeolite nanocrystals with high crystallinity.

In addition to the typical microporous templates, a cyclic diamine template is developed to replace the traditional microporous template to induce the formation of aggregated zeolite nanocrystals [101]. Cyclic diamine cations have the unusual ability to generate and retain the mesoporous structure of the aluminosilicate gel and zeolites during hydrothermal synthesis. Typically, a five- or six-member ring in a cyclic diamine template is a prerequisite for the formation of BEA zeolites; its geometry is well suited for 12-membered ring zeolites, thus placing sufficient restrictions on BEA zeolite. Similarly, pyridine or imidazolyl cation fluids have also been developed for the synthesis of mesoporous zeolites [102].

The solvent effect on the formation of hierarchical zeolites has been reported. Su et al. [103] used silica as the silicon source for in situ crystallization to prepare macroporous-mesoporous-microporous ZSM-5 zeolites and TS-1 zeolites using glycerin as solvent. Glycerin shows a much higher viscosity and lower polarity than water, leading to a weaker solvation capability during hydrothermal synthesis. Abundant zeolite nuclei form in the glycerin system and result in many nanocrystals, which produce mesoporous zeolites via the intergrowth of zeolite crystals. Moreover, the crystallization conditions are more relaxed due to the presence of glycerin and avoid the potential high-pressure hazard of hydrothermal synthesis in aqueous solution. 


\subsubsection{Steam-Assisted Crystallization (SAC) Method}

According to the volatility of the microporous organic templates in the dry gel, the dry gel conversion method can be divided into the vapor-phase transport method and the steam-assisted crystallization method (SAC), respectively [104]. The SAC method is characteristic of the treatment of a dry gel containing a non-volatile microporous template (i.e., tetraethylammonium hydroxide, $\mathrm{TEAOH}$, or TPAOH) in steam: all aluminosilicate and/or silicate species, microporous templates, and alkali cations remain in the solid state throughout crystallization. The use of homogeneous gels as precursors efficiently prevents the inhomogeneous crystallization that frequently occurred in the conventional hydrothermal synthesis method. Therefore, the induction of mesoporous gels can be developed to generate a hierarchical structure for zeolites during the SAC process [105]. Bein et al. [106] proposed a rapid one-step preparation of BEA zeolites with high crystallinity by the SAC method without any mesoporous templates (Figure 3). Due to the high concentration of the reactants within the zeolite xerogel, explosive nucleation occurs during the crystallization process, thereby forming small zeolite crystal nuclei. During the nucleation period, the gel shrinks and partially converts to a zeolite nucleus, which is separated from the gel. In the subsequent crystallization, the remaining gels are transformed into nanocrystals, which are then assembled into aggregates. Thus, a nanoscale Kirkendall effect occurs during the SAC process, and the random assembly of zeolite nanocrystals gives rise to abundant inter-crystalline mesopores $[107,108]$. In particular, benefiting from the significantly higher concentration of microporous template at the surface of amorphous aluminosilicate during the SAC process, a high utilization efficiency of microporous template is achieved in which only a small amount of template is required [107].

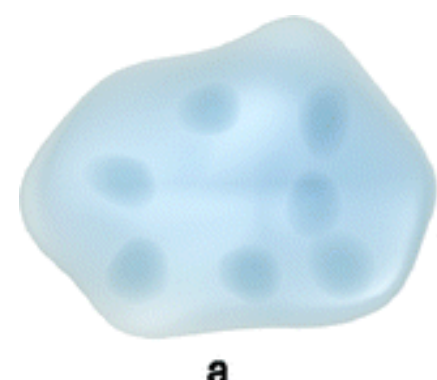

a

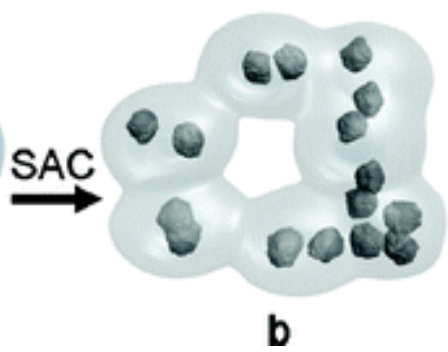

b

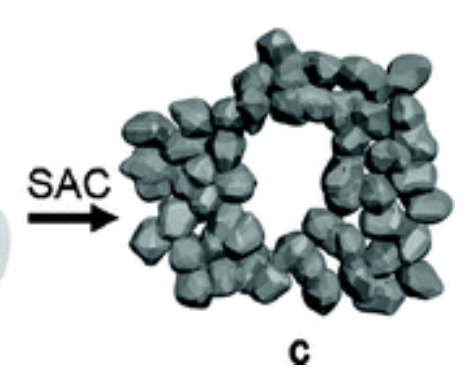

c

Figure 3. Formation of hierarchical BEA zeolite from a dense precursor gel. (a) Dense precursor gel with concentration fluctuations leading to nucleation; (b) contraction (densification) and partial conversion of the gel into nano-sized zeolite crystals after short SAC treatment; at this stage, filtration yields a colloidal solution of BEA zeolite; and (c) continued SAC reaction converts residual gel completely into small aggregated crystallites; the low mobility in the nearly dry environment arrests nanocrystals into a hierarchical zeolite network. (Reprinted with permission from [106]. Copyright: 2011, American Chemical Society).

\subsubsection{Salt-Assisted Seed Induction Method}

For the salt-assisted seed induction method, only a small number of zeolite seeds is required in the concentrated salt system to prepare hierarchical zeolites. The zeolite seeds induce the formation of zeolites with different topologies, and the mineralized salt (i.e., $\mathrm{NaF}$, etc.) regulates the dissolution rate of zeolite seeds and affects the crystallization process. Zhang et al. [109] found that KF can adjust the dissolution of silicalite- 1 seeds in the hydrothermal crystallization process of ZSM- 5 zeolite, thereby obtaining a single-crystal structure ZSM- 5 zeolite with rich intra-crystalline mesopores. When a small amount of microporous template agent (tetrapropylammonium bromide, TPABr) was added, ZSM-5 zeolites with an ordered nanocrystal assembly could be achieved.

The synthesis of hierarchical zeolites with the aid of microporous templates but no mesoporous template is generally achieved with a high solid phase and high alkali contents in a zeolite precursor [110]. In some cases, the use of cyclic diamine to replace traditional microporous templates 
can directly generate a hierarchical structure with micropores and mesopores [111]. These attempts, together with the SAC method, can be adopted to obtain hierarchical zeolites via the intergrowth of zeolite crystalline, thereby forming inter-crystalline mesopores. On the other hand, the salt-assisted seed directed method without any templates can be developed to prepare hierarchical zeolites with intra-crystalline mesopore structures. However, the introduction of toxic ions such as $\mathrm{F}^{-}$has yet to be solved. Table 2 shows the present green synthesis methods for hierarchical MFI zeolites.

Table 2. Methods for the green synthesis of hierarchical MFI zeolites.

\begin{tabular}{|c|c|c|c|c|c|c|c|c|c|c|}
\hline \multirow{2}{*}{ Methods } & \multirow{2}{*}{ Si/Al } & \multicolumn{3}{|c|}{ Surface Area $\left(\mathrm{m}^{2} \mathrm{~g}^{-1}\right)$} & \multicolumn{3}{|c|}{ Pore Volume $\left(\mathrm{cm}^{3} \mathrm{~g}^{-1}\right)$} & \multirow{2}{*}{$\begin{array}{c}\text { Mesopore } \\
\text { Pore Size (nm) }\end{array}$} & \multirow{2}{*}{$\begin{array}{l}\text { Catalytic } \\
\text { Reaction }\end{array}$} & \multirow{2}{*}{ References } \\
\hline & & $\mathrm{S}_{\text {BET }}$ & $S_{\text {ext }}$ & $S_{\text {micro }}$ & $\mathrm{V}_{\text {total }}$ & $\mathrm{V}_{\text {micro }}$ & $\mathrm{V}_{\text {meso }}$ & & & \\
\hline $\begin{array}{c}\mathrm{CaCO}_{3} \text { as hard } \\
\text { template }\end{array}$ & $\infty($ Silicate-1) & 445 & 215 & 230 & 0.40 & 0.10 & 0.30 & $50-100$ & - & [78] \\
\hline $\begin{array}{l}\text { Dual-function } \\
\text { template }\end{array}$ & 30 & 602 & 433 & 179 & 0.56 & 0.057 & $0.50-$ & $7-14$ & $\begin{array}{l}\text { Hydrocarbon } \\
\text { cracking }\end{array}$ & [112] \\
\hline $\begin{array}{c}\text { Intergrowth of } \\
\text { zeolite nanocrystal }\end{array}$ & 50 & $\sim 354$ & $\sim 93$ & $\sim 261$ & 0.26 & 0.13 & 0.13 & $7-10$ & $\begin{array}{l}\text { n-hexane } \\
\text { cracking }\end{array}$ & [88] \\
\hline \multirow{2}{*}{ SAC method } & 20 & 424 & 137 & 287 & $\sim 0.28$ & $\sim 0.13$ & $\sim 0.15$ & 11-15 & - & [110] \\
\hline & 25 & $\sim 385$ & $\sim 52$ & $\sim 333$ & $\sim 0.23$ & $\sim 0.13$ & $\sim 0.1$ & - & $\begin{array}{c}\text { Methanol } \\
\text { aromatization }\end{array}$ & [108] \\
\hline $\begin{array}{l}\text { Salt-assisted seed } \\
\text { induction method }\end{array}$ & 34 & 481 & 87 & 394 & 0.31 & 0.11 & 0.20 & $10-40$ & $\begin{array}{c}\text { O-xylene } \\
\text { isomerization }\end{array}$ & [109] \\
\hline
\end{tabular}

Clearly, the Si / Al ratio and the texture properties of MFI zeolites vary with the synthetic methods. All hierarchical zeolites have a large BET surface area $\left(>350 \mathrm{~m}^{2} \mathrm{~g}^{-1}\right)$ and a large mesopore volume ( $\geq 0.13 \mathrm{~cm}^{3} \mathrm{~g}^{-1}$ versus $<0.1 \mathrm{~cm}^{3} \mathrm{~g}^{-1}$ for conventional MFI zeolites) due to the presence of many mesoporous structures. Hierarchical MFI zeolites synthesized using hard templates tend to show a higher mesopore volume and a larger mesopore pore size. When the MFI zeolite (Silicate-1 [78]) is synthesized using calcium carbonate as the hard template, the largest mesopore volume $\left(0.3 \mathrm{~cm}^{3} / \mathrm{g}\right)$ and pore size $(50-100 \mathrm{~nm})$ are achieved. The hard templates just provide a restriction space for zeolite growth that does not interact with the zeolite precursor during the synthesis process. Thus, these templates can produce a variety of mesoporous structures, from highly ordered and highly networked to isolated and non-interconnected, depending on the structure and arrangement of the template itself during the synthesis process. For instance, a highly ordered hierarchical zeolite can be prepared by using a three-dimensional ordered hard template. It should be noted that the mesopores in hierarchical zeolite using nanoparticles are generally "cave-like" and are embedded in the zeolite crystal rather than open channels, resulting in a small promotion of the diffusion of zeolite. Unlike nanoparticles, the mesoporous channels formed by diameter size controllable nanotubes or nanofibers always start from the external surface and run through zeolite crystals [83], leading to an obvious improvement in the diffusion properties of zeolite.

Unlike a hard template, a soft template mainly relies on the influence of the crystallization process to produce mesopores in zeolites. The soft template method is more variable than the hard template and can also be scaled and functionalized. An early adoption of soft templates is via a traditional surfactant such as cetyltrimethylammonium bromide (CTAB), which can assemble zeolite seeds into mesoporous materials via two steps: synthesis of the zeolite unit with the aid of a microporous template and then assembly of these units around a surfactant. Thus, the mesopore structure depends on the micelle structure of the surfactant. However, the stability of the surfactant micelle structure and the competition of zeolite crystallization and silicate condensation to amorphous silica around the surfactant represent challenging issues in hydrothermal synthesis [113]. Thus, dual-functional templates have been developed and have attracted increasing attention since the work of Ryoo [114]. Ryoo et al. used a long-chain surfactant with bifunctional and di-quaternary ammonium $\mathrm{C}_{6} \mathrm{H}_{13}-\mathrm{N}^{+}\left(\mathrm{CH}_{3}\right)_{2}-\mathrm{C}_{6} \mathrm{H}_{12}-\mathrm{N}^{+}\left(\mathrm{CH}_{3}\right)_{2}-\mathrm{C}_{22} \mathrm{H}_{45}\left(\mathrm{C}_{22-6-6}\right)$ to synthesize hierarchical MFI zeolites in the hydrothermal system, in which the quaternary ammonium salt serves as a directing agent (SDA) for the microporous MFI topology. The $\mathrm{C}_{22}$ tail group has hydrophobic action, exists in the mesoscopic 
micelle structure between the zeolite sheets, inhibits the crystallization of the zeolite in the b-axis direction, and finally forms an ordered MFI zeolite nanosheet. The mesopore structure and size can be adjusted by varying the structure of hydrophobic groups, but even the synthesis of dual-functional templates is usually complex.

Unlike the formation of intra-crystalline mesopores via a mesoporous template, the formation of inter-crystalline mesopores without mesoporous templates should be a relatively low-cost route. However, the resulting zeolite products usually possess a relatively low mesopore volume $\left(0.13-0.2 \mathrm{~cm}^{3} \mathrm{~g}^{-1}\right)$ and a random mesopore size because the inter-crystalline mesopore is randomly formed by the aggregation of zeolite crystals. Table 2 shows that MFI zeolites prepared by the intergrowth of zeolite crystals possess lower BET and external surface areas, total pore, and mesopore volume than MFI zeolites from other synthetic strategies. Therefore, efficient green methods for the formation of an intra-crystalline mesopores are still required, and the development of sustainable mesoporous templates or mineralized salts is desired.

\section{Conclusions and Outlook}

Here we summarized progress on the green synthesis of zeolites by developing sustainable raw silicon and aluminum sources, avoiding or reducing microporous organic templates, and exploiting facile synthesis methods. For the hydrothermal crystallization of zeolites in solution chemistry, in addition to the greenhouse gas emissions problem and the high energy consumption during calcination, recycling reagents in the residual solution and treatment of water pollution are challenging concerns for green synthesis. Thus, the utilization of a mother liquid after hydrothermal synthesis should be a focus in the industrial mass production of zeolites. On the other hand, the synthetic route via solid-state or quasi-solid-state synthesis (i.e., both template-free and solvent-free routes) appears to be a sustainable choice without water pollution concerns. However, the mass production of zeolites followed by solvent-free (solid-state synthesis) or SAC synthesis (quasi-solid-state synthesis) routes is still challenging because of the difficulty of the heat and mass transfer involving solid-state reactions. Continuous-flow synthesis and microwave-assisted synthesis methods indeed promote production efficiency by enhancing heat transfer, and their application in solid-state synthesis or quasi-solid-state is worthwhile.

Hierarchical zeolites have been widely studied due to their excellent catalytic performance, especially the enhanced catalyst lifetime for potential industrial applications. At present, a great progress has been made in the direct synthesis of hierarchical zeolites via hydrothermal synthesis. The induction of mesoporous templates for composing hierarchical zeolites inevitably involves removing, separating, and recycling mesopore and microporous templates, leading to problems with energy consumption and pollution. Unlike the synthesis route using mesoporous templates, the method that does not use mesoporous templates is the greener choice because it avoids expensive and toxic organic mesoporous templates and reduces water and microporous organic template consumption when the synthesis is done by the solid- and quasi-solid-phase synthesis methods.

Considering the current progress in the green synthesis of zeolites, three problems in terms of the sustainable synthesis of hierarchical zeolites can be noted. First, the synchronization of the present synthetic strategies for hierarchical zeolites with the use of natural/sustainable raw materials (i.e., kaolin, diatomite, coal ash, etc.) as a zeolite precursor should be studied. Second, the synthesis route without any organic templates should be further improved to be applicable for more topological zeolite types with a controllable $\mathrm{Si} / \mathrm{Al}$ ratio as well as texture properties. This route is still a great challenge for conventional microporous zeolites, let alone hierarchical zeolites. The introduction of crystallization seeds seems to be a feasible solution, in which the composition of the zeolite precursor and the crystallization condition are required to screen. Last, the development of facile synthesis methods for hierarchical zeolite synthesis is required. For instance, the combination of solid-state or quasi-solid-state synthesis with the aid of a microwave can be considered because of the high crystallization rate and high product yield. 
Author Contributions: The first two authors contributed equally to the work.

Funding: This research was funded by the National Natural Science Foundation of China (U1662131 and 21206192) and the Science Foundation of China University of Petroleum-Beijing (C201603).

Conflicts of Interest: The authors declare no conflict of interest.

\section{References}

1. Holm, M.S.; Taarning, E.; Egeblad, K.; Christensen, C.H. Catalysis with hierarchical zeolites. Catal. Today 2011, 168, 3-16. [CrossRef]

2. Hartmann, M.; Machoke, A.G.; Schwieger, W. Catalytic test reactions for the evaluation of hierarchical zeolites. Chem. Soc. Rev. 2016, 45, 3313-3330.

3. Jia, L.Y.; Raad, M.; Hamieh, S.; Toufaily, J. Catalytic fast pyrolysis of biomass: Superior selectivity of hierarchical zeolites to aromatics. Green Chem. 2017, 19, 5442-5459. [CrossRef]

4. Park, D.H.; Kim, S.S.; Wang, H.; Pinnavaia, T.J.; Papapetrou, M.C.; Lappas, A.A.; Triantafyllidis, K.S. Selective petroleum refining over a zeolite catalyst with small intracrystal mesopores. Angew. Chem. Int. Ed. 2009, 48, 7645-7648. [CrossRef]

5. Choi, M.; Na, K.; Ryoo, R. The synthesis of a hierarchically porous BEA zeolite pseudomorphic crystallization. Chem. Commum. 2009, 20, 2845-2847. [CrossRef] [PubMed]

6. Wei, Y.; Parmentier, T.E.; de Jong, K.P.; Zečević, J. Tailoring and visualizing the pore architecture of hierarchical zeolites. Chem. Soc. Rev. 2015, 44, 7234-7261. [CrossRef] [PubMed]

7. Zhu, X.C.; Rohling, R.; Filonenko, G.; Mezari, B.; Hofmann, J.P.; Asahina, S.; Hensen, E.J.M. Synthesis of hierarchical zeolites using an inexpensive mono-quaternary ammonium surfactant as mesoporogen. Chem. Commun. 2014, 50, 14658-14661.

8. Verboekend, D.; Pérez-Ramírez, J. Towards a sustainable manufacture of hierarchical zeolites. ChemSusChem 2014, 7, 753-764. [PubMed]

9. Ogura, M.; Shinomiya, S.Y.; Tateno, J.; Nara, Y.; Kikuchi, E.; Matsukata, M. Formation of uniform mesopores in ZSM-5 zeolite through treatment in alkaline solution. Chem. Lett. 2000, 29, 882-883. [CrossRef]

10. Huang, L.; Wang, Z.; Sun, J.; Miao, L.; Li, Q.; Yan, Y.; Zhao, D. Fabrication of ordered porous structures by self-assembly of zeolite nanocrystals. J. Am. Chem. Soc. 2000, 122, 3530-3531. [CrossRef]

11. Meng, X.J.; Xiao, F.S. Green Routes for Synthesis of Zeolites. Chem. Rev. 2014, 114, 1521-1543. [CrossRef] [PubMed]

12. Lehman, S.E.; Larsen, S.C. Zeolite and mesoporous silica nanomaterials: Greener syntheses, environmental applications and biological toxicity. Environ. Sci. Nano 2014, 1, 200-213. [CrossRef]

13. Abdullahi, T.; Harun, Z.; Othman, M.H.D. A review on sustainable synthesis of zeolite from kaolinite resources via hydrothermal process. Adv. Powder Technol. 2017, 28, 1827-1840. [CrossRef]

14. Pan, F.; Lu, X.; Wang, Y.; Chen, S.; Yan, Y. Organic template-free synthesis of ZSM-5 zeolite from coal-series kaolinite. Mater. Lett. 2014, 115, 5-8. [CrossRef]

15. Pan, F.; Lu, X.C.; Wang, Y.; Chen, S.W.; Wang, T.Z.; Yan, Y. Synthesis and crystallization kinetics of ZSM-5 without organic template from coal-series kaolinite. Microporous Mesoporous Mater. 2014, 184, 134-140.

16. Li, X.; Li, B.; Xu, J.; Wang, Q.; Pang, X.; Gao, X.; Zhou, Z.; Piao, J. Synthesis and characterization of Ln-ZSM-5/MCM-41 (Ln = La, Ce) by using kaolin as raw material. Appl. Clay Sci. 2010, 50, 81-86. [CrossRef]

17. Chaisena, A.; Rangsriwatananon, K. Synthesis of sodium zeolites from natural and modified diatomite. Mater. Lett. 2005, 59, 1474-1479. [CrossRef]

18. Rangsriwatananon, K.; Chaisena, A.; Thongkasam, C. Thermal and acid treatment on natural raw diatomite influencing in synthesis of sodium zeolites. J. Porous Mater. 2008, 15, 499-505.

19. Zhang, K.; Liu, Y.; Zhao, J.; Liu, C. Hierarchical porous ZSM-5 zeolite synthesized by in situ zeolitization and its coke deposition resistance in aromatization reaction. Chin. J. Chem. 2012, 30, 597-603. [CrossRef]

20. Zhang, K.; Liu, Y.Q.; Zhao, J.C.; Liu, C.G. Zeolitization of Diatomite to Prepare Hierarchical Porous ZSM-5 Zeolite through Solid Phase in Situ Process. Non-Met. Mine 2011, 34, 1-5.

21. Zhang, K.; Liu, Y.; Tian, S.; Zhao, E.; Zhang, J.; Liu, C. Preparation of bifunctional $\mathrm{NiPb} / \mathrm{ZnO}$-diatomite-ZSM-5 catalyst and its reactive adsorption desulfurization coupling aromatization performance in FCC gasoline upgrading process. Fuel 2013, 104, 201-207. [CrossRef] 
22. Jia, Y.; Han, W.; Xiong, G.; Yang, W. A method for diatomite zeolitization through steam-assisted crystallization with in-situ seed. Mater. Lett. 2008, 62, 2400-2403.

23. Li, X.Y.; Jiang, Y.; Liu, X.Q.; Shi, L.Y.; Zhang, D.Y.; Sun, L.B. Direct synthesis of zeolites from a natural clay, attapulaite. ACS Sustain. Chem. Eng. 2017, 5, 6124-6230.

24. Missengue, R.N.M.; Losch, P.; Musyoka, N.M.; Louis, B.; Pale, P.; Petrik, L.F. Conversion of South African Coal Fly Ash into High-Purity ZSM-5 Zeolite without Additional Source of Silica or Alumina and Its Application as a Methanol-to-Olefins Catalyst. Catalysts 2018, 8, 124. [CrossRef]

25. Liu, Y.; Yan, C.J.; Zhao, J.J.; Zhang, Z.H.; Wang, H.Q.; Zhou, S.; Wu, L.M. Synthesis of zeolite P1 from fly ash under solvent-free condition for ammonium removal from water. J. Clean. Prod. 2018, 202, 11-22.

26. Zhang, C.Q.; Li, S.; Bao, S.C. Sustainable synthesis of ZSM-5 zeoltie from Rice Husk Ash without addition of solvents. Waste Biomass Valoriz. 2018, 1-11. [CrossRef]

27. Mehmandoust, G.; Pourahmad, A. Preparation of ZSM-12 zeolite from RHS and Its Application for Synthesis of n-type ZnO Semiconductor Nanoparticles: A Green Chemistry Approach. J. Inorg. Organomet. Polym. Mater. 2018, 28, 2213-2220. [CrossRef]

28. Zhang, C.Q.; Li, S.Q.; Bao, S.C. A facile and green method for the synthesis of hierarchical ZSM-5 zeolite aggregates from rice husk ash. Res. Chem. Intermed. 2018, 44, 3581-3595.

29. Meng, X.J.; Wang, L.; Xiao, F.S. Chapter 11 Sustainable Routes for Synthesis of Zeolite Catalysts. In Nanotechnology in Catalysis: Applications in the Chemical Industry, Energy Development, and Environment Protection; Sels, B., van de Voorde, M., Eds.; Wiley-VCH Verlag GmbH \& Co. KGaA: Weinheim, Germany, 2017.

30. Jones, C.W.; Tsuji, K.; Takewaki, T.; Beck, L.W.; Davis, M.E. Tailoring molecular sieve properties during SDA removal via solvent extraction. Microporous Mesoporous Mater. 2001, 48, 57-64.

31. Jones, C.W.; Hwang, S.J.; Okubo, T.; Davis, M.E. Synthesis of hydrophobic molecular sieves by hydrothermal treatment with acetic acid. Chem. Mater. 2001, 13, 1041-1050. [CrossRef]

32. Takewaki, T.; Beck, L.W.; Davis, M.R. Synthesis of CIT-6, a zincosilicate with the BEA topology. Top. Catal. $1999,9,35-42$.

33. Wang, J.Y.; Song, J.W.; Yin, C.Y.; Ji, Y.Y.; Zou, Y.C.; Xiao, F.S. Tetramethylguanidine-templated synthesis of aluminophosphate-based microporous crystals with AFI-type structure. Microporour Mesoporour Mater. 2009, 117, 561-569.

34. Flanigen, E.M.; Grose, R.W. Phosphorus substitution in zeolite frameworks. In Proceedings of the Second International Conference on Molecular Sieve Zeolites, Worcester, MA, USA, 8-11 September 1970; American Chemical Society: Washington, DC, USA, 1970; pp. 71-94.

35. Grose, R.W.; Flanigen, E.M. Novel Zeolite Compositions and Processes for Preparing and Using Same. U.S. Patent 4257885, 24 March 1981.

36. Li, H.X.; Xiang, S.H.; Liu, S.Q.; Wu, D.M.; Liu, Y.T.; Zhang, X.S. “Direct Method” for the Synthesis of ZSM-5 Zeolite. Chinese Patent CN85100463, 3 April 1985.

37. Song, J.; Dai, L.; Ji, Y.; Xiao, F.S. Organic template-free synthesis of aluminosilicate zeolite ECR-1. Chem. Mater. 2006, 18, 2775-2777. [CrossRef]

38. Rubin, M.K.; Rosinski, E.J.; Plank, C.J. Hydrocarbon Conversion with Crystalline Zeolite ZSM-34. U.S. Patent 4116813, 26 September 1978.

39. Wu, Z.; Song, J.; Ji, Y.; Ren, L.; Xiao, F.S. Organic template-free synthesis of ZSM-34 zeolite from an assistance of zeolite L seeds solution. Chem. Mater. 2008, 20, 357-359. [CrossRef]

40. Zhang, L.; Yang, C.; Meng, X.; Xie, B.; Wang, L.; Ren, L.; Ma, S.; Xiao, F.S. Organotemplate-free syntheses of ZSM-34 zeolite and its heteroatom-substituted analogues with good catalytic performance. Chem. Mater. 2010, 22, 3099-3107. [CrossRef]

41. Xie, B.; Song, J.; Ren, L.; Ji, Y.; Li, J.; Xiao, F.S. Organic template-free and fast route for synthesizing beta zeolite. Chem. Mater. 2008, 20, 4533-4535. [CrossRef]

42. Sano, T.; Itakura, M.; Sadakane, M. High potential of interzeolite conversion method for zeolite synthesis. J. Jpn. Pet. Inst. 2013, 56, 183-197.

43. Goel, S.; Zones, S.I.; Iglesia, E. Synthesis of zeolites via interzeolite transformations without organic structure-directing agents. Chem. Mater. 2015, 27, 2056-2066. [CrossRef]

44. Sachse, A.; García-Martínez, J. Surfacant-Templating of Zeolites: From Design to Application. Chem. Mater. 2017, 29, 3827-3853. 
45. Cooper, E.R.; Andrews, C.D.; Wheatley, P.S.; Webb, P.B.; Wormald, P.; Morris, R.E. Ionic liquids and eutectic mixtures as solvent and template in synthesis of zeolite analogues. Nature 2004, 430, 1012-1016. [CrossRef]

46. Wragg, D.S.; Byrne, P.J.; Giriat, G.; Ouay, B.L.; Gyepes, R.; Harrison, A.; Whittaker, A.G.; Morris, R.E. In situ comparison of lonothermal kinetics under microwave and conventional heating. J. Phys. Chem. C 2009, 113, 20553-20558. [CrossRef]

47. Pamham, E.R.; Morris, R.E. The ionothermal synthesis of cobalt aluminophosphate zeolite frameworks. J. Am. Chem. Soc. 2006, 128, 2204-2205.

48. Xu, W.; Dong, J.; Li, J.; Li, J.; Wu, F. A novel method for the preparation of zeolite ZSM-5. J. Chem. Soc. Chem. Commun. 1990, 21, 755-756. [CrossRef]

49. Li, H.Y.; Dou, T.; Gong, Y.J.; Tian, R. Synthesis of ZSM-5 zeolite with special morphology in extra concentrated system and its crystallization mechanism study. Pet. Process. Petrochem. 2010, 41, 40-46.

50. Ji, Y.Y.; Zhang, B.; Zhang, W.; Zhao, B.; Li, H.B.; Wang, D.M.; Li, Y. High-efficient synthesis of zeolite LTA via a wet-gel crystallization route. Chem. Res. Chin. Univ. 2017, 33, 520-524. [CrossRef]

51. Ren, L.; Wu, Q.; Yang, C.; Zhu, L.; Li, C.; Zhang, P.; Zhang, H.; Meng, X.; Xiao, F.S. Solvent-free synthesis of zeolites from solid raw materials. J. Am. Chem. Soc. 2012, 134, 15173-15176. [CrossRef]

52. Jin, Y.; Sun, Q.; Qi, G.; Yang, C.; Xu, J.; Chen, F.; Meng, X.; Deng, F.; Xiao, F.S. Solvent-free synthesis of silicoaluminophosphate zeolites. Angew. Chem. Int. Ed. 2013, 52, 9172-9175.

53. Wu, Q.M.; Meng, X.J.; Gao, X.H.; Xiao, F.S. Solvent-Free Synthesis of Zeolites: Mechanism and Utility. Acc. Chem. Res. 2018, 51, 1396-1403. [CrossRef]

54. Wang, Y.Q.; Wu, Q.M.; Meng, X.J.; Xiao, F.S. Insights into the organotemplate-free synthesis of zeolite catalysts. Engineering 2017, 3, 567-574. [CrossRef]

55. Wu, Q.M.; Liu, X.L.; Zhu, L.F.; Meng, X.J.; Deng, F.; Fan, F.T.; Feng, Z.C.; Li, C.; Maurer, S.; Feyen, M.; et al. Solvent-free synthesis of ITQ-12, ITQ-13, and ITQ-17 zeolites. Chin. J. Chem. 2017, 35, 572-576. [CrossRef]

56. Li, M.; Wang, Y.H.; Bai, L.; Chang, N.; Nan, G.Z.; Hu, D.; Zhang, Y.F.; Wei, W. Solvent-free synthesis of SAPO-34 nanocrystals with reduced template consumption for methanol-to-olefins process. Appl. Catal. A 2017, 531, 203-311.

57. Petkowicz, D.I.; Canal, S.; Finger, P.H.; Mignoni, M.L.; dos Santos, J.H.Z. Synthesis of hybrid zeolites using a solvent-free method in the presence of different organosilanes. Microporous Mesoporous Mater. 2017, 241, 98-106.

58. Xiao, Y.C.; Sheng, N.; Chu, Y.Y.; Wang, Y.Q.; Wu, Q.M.; Liu, X.L.; Deng, F.; Meng, X.J.; Feng, Z.C. Mechanism on solvent-free crystallization of NaA zeolite. Microporous Mesoporous Mater. 2017, 237, 201-209. [CrossRef]

59. Cui, Y.C.; Yan, Z.; Li, M.L.; Zhu, J.; Zhu, L.F.; Yao, H.; Cao, X.B. Solvent-free synthesis of all silica beta zeolite in the presence of tetraethylammonium bromide. Crystals 2018, 8, 73.

60. Cheng, S.L.; Mazonde, B.; Zhang, G.N.; Javed, M.; Dai, P.; Cao, Y.N.; Tu, S.S.; Wu, J.Y.; Lu, C.X.; Xing, C.; et al. Co-based MOR/ZSM-5 composite zeolites over a solvent-free synthesis strategy for improving gasoline selectivity. Fuel 2018, 223, 354-359. [CrossRef]

61. Bian, C.Q.; Chen, F.; Zhang, L.; Zhang, W.P.; Meng, X.J.; Maurer, S.; Dai, D.; Parvulescu, A.N.; Muller, U.; Xiao, F.S. Enhance synthetic efficiency of CHA zeolite crystallized at higher temperature. Catal. Today 2018, 316, 31-36.

62. Chu, P.; Dwyer, F.G.; Vartuli, X. Crystallization Method Employing Microwave Radiation. U.S. Patent 4778666, 10 October 1988.

63. Girnus, I.; Jancke, K.; Vetter, R.; Richter-Mendau, J.; Caro, J. Large $\mathrm{AlPO}_{4}-5$ crystals by microwave heating. Zeolites 1995, 15, 33-39.

64. Fang, M.; Du, H.; Xu, W.; Meng, X.; Pang, W. Microwave preparation of molecular sieve AlPO4-5 with nanometer sizes. Microporous Mater. 1997, 9, 59-61. [CrossRef]

65. Chen, X.; Yan, W.; Shen, W.; Yu, J.; Cao, X.; Xu, R. Morphology control of self-stacked silicalite-1 crystals using microwave-assisted solvothermal synthesis. Microporous Mesoporous Mater. 2007, 104, 296-304.

66. Majano, S.; Gerardo, J.; Delmotte, L.; Valtchev, V.; Mintova, S. Al-rich zeolite Beta by seeding in the absence of organic template. Chem. Mater. 2009, 21, 4184-4191.

67. Li, Y.; Yang, W. Microwave synthesis of zeolite membranes: A review. J. Membr. Sci. 2008, 316, 3-17. [CrossRef]

68. Reinoso, D.; Adrover, M.; Pedernera, M. Green synthesis of nanocrystalline faujasite zeolite. Ultrason. Sonochem. 2018, 42, 303-309. 
69. Liu, Z.D.; Okabe, K.; Anand, C.; Yonezawa, Y.; Zhu, J.; Yamada, H.; Endo, A.; Yanaba, Y.; Yoshikawa, T.; Ohara, K.; et al. Continuous flow synthesis of ZSM-5 zeolite on the order of seconds. Proc. Natl. Acad. Sci. USA 2016, 113, 14267-14271. [PubMed]

70. Zhu, J.; Liu, Z.D.; Endo, A.; Yanaba, Y.; Yoshikawa, T.; Wakihara, T.; Okubo, T. Ultrafast, OSDA-free synthesis of mordenite zeolite. CrysEngComm 2017, 19, 632-640.

71. Zhu, J.; Liu, Z.; Sukenaga, S.; Ando, M.; Shibata, H.; Okubo, T.; Wakihara, T. Ultrafast synthesis of *BEA zeolite without the aid of aging pretreatment. Microporous Mesoporous Mater. 2018, 248, 1-8.

72. Zhang, K.; Ostraat, M.L. Innovations in hierarchical zeolite synthesis. Catal. Today 2016, 264, 3-15. [CrossRef]

73. Song, Y.; Hua, Z.; Zhu, Y.; Zhou, J.; Zhou, X.; Liu, Z.; Shi, J. Solvent-free liquid phase tert-butylation of phenol over hierarchical ZSM-5 zeolites for the efficient production of 2,4-ditertbutylphenol. J. Mater. Chem. 2012, 22, 3327-3329.

74. Zhou, J.; Hua, Z.; Cui, X.; Ye, Z.; Cui, F.; Shi, J. Hierarchical mesoporous TS-1 zeolite: A highly active and extraordinarily stable catalyst for the selective oxidation of 2,3, 6-trimethylphenol. Chem. Commun. 2010, 46, 4994-4996. [CrossRef] [PubMed]

75. Zhou, J.; Hua, Z.; Liu, Z.; Wu, W.; Zhu, Y.; Shi, J. Direct synthetic strategy of mesoporous ZSM-5 zeolites by using conventional block copolymer templates and the improved catalytic properties. ACS Catal. 2011, 1, 287-291. [CrossRef]

76. Machoke, A.G.; Beltrán, A.M.; Inayat, A.; Winter, B.; Weissenberger, T.; Kruse, N.; Guttel, R.; Spiecker, E.; Schwieger, W. Micro/macroporous system: MFI-type zeolite crystals with embedded macropores. Adv. Mater. 2015, 27, 1066-1070. [CrossRef] [PubMed]

77. Song, Y.; Hua, Z.; Zhu, Y.; Zhou, X.; Wu, W.; Zhang, L.; Shi, J. An in situ carbonaceous mesopore template for the synthesis of hierarchical ZSM-5 zeolites by one-pot steam-assisted crystallization. Chem. Asian J. 2012, 7, 2772-2776. [CrossRef] [PubMed]

78. Zhu, H.; Liu, Z.; Wang, Y.; Kong, D.; Yuan, X.; Xie, Z. Nanosized $\mathrm{CaCO}_{3}$ as hard template for creation of intracrystal pores within Silicalite-1 crystal. Chem. Mater. 2008, 20, 1134-1139. [CrossRef]

79. Pal, N.; Bhaumik, A. Soft templating strategies for the synthesis of mesoporous materials: Inorganic, organic-inorganic hybrid and purely organic solids. Adv. Colloid Interface Sci. 2013, 189-190, $21-41$.

80. Xiao, F.S.; Wang, L.; Yin, C.; Lin, K.; Di, Y.; Li, J.; Xu, R.; Su, D.S.; Schologl, R.; Yokoi, T.; et al. Catalytic properties of hierarchical mesoporous zeolites templated with a mixture of small organic ammonium salts and mesoscale cationic polymers. Angew. Chem. Int. Ed. 2006, 118, 3162-3165. [CrossRef]

81. Zhu, J.; Zhu, Y.; Zhu, L.; Rigutto, M.; Made, A.; Yang, C.; Pan, S.; Wang, L.; Zhu, L.; Jin, Y.; et al. Highly Mesoporous Single-Crystalline Zeolite Beta Synthesized Using a Nonsurfactant Cationic Polymer as a Dual-Function Template. J. Am. Chem. Soc. 2014, 136, 2503-2510. [CrossRef] [PubMed]

82. Jin, J.; Zhang, X.; Li, Y.; Li, H.; Wu, W.; Cui, Y.; Chen, Q.; Li, L.; Gu, J.; Zhao, W.; et al. A simple route to synthesize mesoporous ZSM-5 templated by ammonium-modified chitosan. Chem. Eur. J. 2012, 18, 16549-16555. [CrossRef] [PubMed]

83. Wang, Q.; Xu, S.; Chen, J.; Wei, Y.; Li, J.; Fan, D.; Yu, Z.; Qi, Y.; He, Y.; Xu, S.; et al. Synthesis of mesoporous ZSM-5 catalysts using different mesoporous templates and their application in methanol conversion for enhanced catalyst lifespan. RSC Adv. 2014, 4, 21479-21491.

84. Karlsson, A.; Stocker, M.; Schmidt, R. Composites of micro- and mesoporous materials: Simultaneous syntheses of MFI/MCM-41 like phases by a mixed template approach. Microporous Mesoporous Mater. 1999, 27, 181-192. [CrossRef]

85. Serrano, D.P.; Aguado, J.; Escola, J.M.; Rodríguez, J.M.; Peral, Á. Hierarchical zeolites with enhanced textural and catalytic properties synthesized from organofunctionalized seeds. Chem. Mater. 2006, 18, 2462-2464. [CrossRef]

86. Miyake, K.; Hirota, Y.; Uchida, Y.; Nishiyama, N. Synthesis of mesoporous MFI zeolite using PVA as a secondary template. J. Porous Mater. 2016, 23, 1395-1399. [CrossRef]

87. Zhu, H.; Liu, Z.; Kong, D.; Wang, Y.; Xie, Z. Synthesis and catalytic performances of mesoporous zeolites templated by polyvinyl butyral gel as the mesopore directing agent. J. Phys. Chem. C 2008, 112, 17257-17264. [CrossRef]

88. Li, W.; Ma, T.; Zhang, Y.; Gong, Y.; Wu, Z.; Dou, T. Facile control of inter-crystalline porosity in the synthesis of size-controlled mesoporous MFI zeolites via in-situ converting silica gel into zeolite nanocrystals for catalytic cracking. CrystEngComm 2015, 17, 5680-5689. [CrossRef] 
89. Zhang, X.; Liu, D.; Xu, D.; Asahina, S.; Cychosz, K.A.; Agrawal, K.V.; AI Wahedi, Y.; Bhan, A.; AI Hashimi, S.; Terasaki, O.; et al. Synthesis of self-pillared zeolite nanosheets by repetitive branching. Science 2012, 336, 1684-1687. [CrossRef] [PubMed]

90. Moller, K.; Yilmaz, B.; Muller, U.; Bein, T. Nanofusion: Mesoporous zeolites made easy. Chem. Eur. J. 2012, 18, 7671-7674. [CrossRef] [PubMed]

91. Wang, X.; Li, Y.; Luo, C.; Liu, J.; Chen, B. Direct synthesis of hierarchical zeolites with oriented nanocrystals without adding extra templates. RSC Adv. 2013, 3, 6295-6298. [CrossRef]

92. Luo, W.; Yang, X.Y.; Wang, Z.R.; Huang, W.F.; Chen, J.Y.; Jiang, W.; Wang, L.J.; Cheng, X.W.; Deng, Y.H.; Zhao, D.Y. Synthesis of ZSM-5 aggregates made of zeolite nanocrystals through a simple solvent-free method. Microporous Mesoporous Mater. 2017, 243, 112-118. [CrossRef]

93. Zhang, C.S.; Wu, Q.M.; Lei, C.; Pan, S.X.; Bian, C.Q.; Wang, L.; Meng, X.J.; Xiao, F.S. Solvent-free and mesoporogen-free synthesis of mesoporous aluminosilicate ZSM-5 zeolites with superior catalytic properties in the methanol-to-olefins reaction. Ind. Eng. Chem. Res. 2017, 56, 1450-1460. [CrossRef]

94. Bai, L.; Liu, C.; Li, M.; Wang, Y.H.; Nan, G.Z.; Hu, D.; Zhang, Y.F.; Zeng, G.F.; Wei, W.; Sun, Y. Synthesis of all-silica DDR zeolite in an environment-friendly way. Microporous Mesoporous Mater. 2017, 239, 34-39. [CrossRef]

95. Yue, Y.Y.; Gu, L.L.; Zhou, Y.N.; Liu, H.Y.; Yuan, P.; Zhu, H.B.; Bai, Z.; Bao, X.J. Template-free synthesis and catalytic applications of microporous and hierarchical ZSM-5 zeoltie from natural aluminosilicate minerals. Ind. Eng. Chem. Res. 2017, 56, 10069-10077. [CrossRef]

96. Kovo, A.S.; Opuama, E.; Edoga, M.O.; Abdulkadir, M.; Isah, A.G.; Mohammed, I.A. On the synthesis of zeolitey Y /ZSM-5 composite via novel technique. Chem. Eng. Sci. 2016, 4, 1-4.

97. Mintova, S.; Gilson, J.P.; Valtchev, V. Advances in nanosized zeolites. Nanoscale 2013, 5, 6693-6703. [CrossRef]

98. Ng, E.P.; Delmotte, L.; Mintova, S. Environmentally benign synthesis of nanosized aluminophosphate enhanced by microwave heating. Green Chem. 2008, 10, 1043-1048. [CrossRef]

99. Van Heyden, H.; Mintova, S.; Bein, T. AlPO-18 nanocrystals synthesized under microwave irradiation. J. Mater. Chem. 2006, 16, 514-518. [CrossRef]

100. Wakihara, T.; Tatami, J. Top-down Tuning of Nanosized Zeolites by Bead-milling and Recrystallization. J. Jpn. Pet. Inst. 2013, 56, 206-213. [CrossRef]

101. Na, K.; Choi, M.; Ryoo, R. Cyclic diquaternary ammoniums for nanocrystalline BEA, MTW and MFI zeolites with intercrystalline mesoporosity. J. Mater. Chem. 2009, 19, 6713-6719. [CrossRef]

102. Kore, R.; Satpati, B.; Srivastava, R. Synthesis of dicationic ionic liquids and their application in the preparation of hierarchical zeolite Beta. Chem. Eur. J. 2011, 17, 14360-14365. [CrossRef]

103. Yang, X.Y.; Tian, G.; Chen, L.H.; Li, Y.; Rooke, J.C.; Wei, Y.X.; Liu, Z.M.; Deng, Z.; Tendeloo, G.V.; Su, B.L. Well-organized zeolite nanocrystal aggregates with interconnected hierarchically micro-meso-macropore systems showing enhanced catalytic performance. Chemistry 2015, 17, 14987-14995. [CrossRef] [PubMed]

104. Matsukata, M.; Osaki, T.; Ogura, M.; Kikuchi, E. Crystallization behavior of zeolite Beta during steam-assisted crystallization of dry gel. Microporous Mesoporous Mater. 2002, 56, 1-10. [CrossRef]

105. Zhou, J.; Hua, Z.; Zhao, J.; Gao, Z.; Zeng, S.; Shi, J. A micro/mesoporous aluminosilicate: Key factors affecting framework crystallization during steam-assisted synthesis and its catalytic property. J. Mater. Chem. 2010, 20, 6764-6771. [CrossRef]

106. Moller, K.; Yilmaz, B.; Jacubinas, R.M.; Muller, U.; Bein, T. One-step synthesis of hierarchical zeolite Beta via network formation of uniform nanocrystals. J. Am. Chem. Soc. 2011, 133, 5284-5295. [CrossRef]

107. Zhang, J.L.; Cao, P.; Yan, H.Y.; Wu, Z.J.; Dou, T. Synthesis of hierarchical zeolite Beta with low organic template content via the steam-assisted conversion method. Chem. Eng. J. 2016, 291, 82-93. [CrossRef]

108. Jia, Y.M.; Wang, J.W.; Zhang, K.; Chen, G.L.; Yang, Y.F.; Liu, S.B.; Ding, C.M.; Meng, Y.Y.; Liu, P. Hierarchical ZSM-5 zeoltie synthesized via dry gel conversion-steam assisted crystallization process and its application in aromatization of methanol. Powder Technol. 2018, 328, 415-429. [CrossRef]

109. Zhang, H.; Song, K.; Wang, L.; Zhang, H.; Zhang, Y.; Tang, Y. Organic structure directing agent-free and seed-induced synthesis of enriched intracrystal mesoporous ZSM-5 zeolite for shape-selective reaction. ChemCatChem 2013, 5, 2874-2878. [CrossRef]

110. Li, C.; Wang, Y.; Shi, B.; Ren, J.; Lu, G. Synthesis of hierarchical MFI zeolite microspheres with stacking nanocrystals. Microporous Mesoporous Mater. 2009, 117, 104-110. [CrossRef] 
111. Tao, Y.S.; Kanoh, H.; Kaneko, K. ZSM-5 monolith of uniform mesoporous channels. J. Am. Chem. Soc. 2003, 125, 6044-6045. [CrossRef] [PubMed]

112. Dong, X.L.; Shaikh, S.; Vittenet, J.R.; Wang, J.J.; Liu, Z.H.; Bhatte, K.D.; Ali, O.; Xu, W.; Osorio, I.; Saih, Y.; et al. Fine Tuning the Diffusion Length in Hierarchical ZSM-5 To Maximize the Yield of Propylene in Catalytic Cracking of Hydrocarbons. ACS Sustain. Chem. Eng. 2018, 6, 15832-15840. [CrossRef]

113. Li, H.; Jin, J.; Wu, W.; Chen, C.C.; Li, L.; Li, Y.S.; Zhao, W.R.; Gu, J.L.; Chen, G.R.; Shi, J.L. Synthesis of a hierarchically macro-/mesoporous zeolite based on a micro-emulsion mechanism. J. Mater. Chem. 2011, 21, 19395-19401. [CrossRef]

114. Choi, M.; Na, K.; Kim, J.; Sakamoto, Y.; Terasaki, O.; Ryoo, R. Stable single-unit-cell nanosheets of zeolite MFI as active and long-lived catalysts. Nature 2009, 461, 246-249. [CrossRef]

C 2019 by the authors. Licensee MDPI, Basel, Switzerland. This article is an open access article distributed under the terms and conditions of the Creative Commons Attribution (CC BY) license (http:// creativecommons.org/licenses/by/4.0/). 